This document is confidential and is proprietary to the American Chemical Society and its authors. Do not copy or disclose without written permission. If you have received this item in error, notify the sender and delete all copies.

\title{
Multiple substitution strategies toward tunable luminescence in Lu2MgAl4SiO12:Eu2+ phosphors
}

\begin{tabular}{|r|l|}
\hline Journal: & Inorganic Chemistry \\
\hline Manuscript ID & ic-2019-031428 \\
\hline Manuscript Type: & Article \\
\hline Author: & 27-Oct-2019 \\
\hline Complete List of Authors: & $\begin{array}{l}\text { Ming, Zhqiang; University of Science and Technology Beijing, School of } \\
\text { Materials Sciences and Engineering } \\
\text { Qiao, Jianwei; University of Science and Technology Beijing, School of } \\
\text { Materials Sciences and Engineering } \\
\text { Molokeev, Maxim; Institut fiziki imeni Kirenskogo SO RAN, } \\
\text { Zhao, Jing; University of Science and Technology Beijing, School of } \\
\text { Materials Sciences and Engineering } \\
\text { Swart, Hendrik; University of the Free State, Physics } \\
\text { Xia, Zhiguo; University of Science and Technology Beijing, School of } \\
\text { Materials Sciences and Engineering }\end{array}$ \\
\hline
\end{tabular}

\section{SCHOLARONE Manuscripts}




\section{INTRODUCTION}

Phosphor-converted white light-emitting diodes (wLEDs) have received a growing attention due to their superior performance such as low energy consumption, wide color tenability, and long duration time ${ }^{1,2}$. For obtaining ideal w-LEDs, it is essential to improve the characteristic photoluminescence (PL) properties of phosphor materials, since the used phosphor materials significantly affect the performance of $\mathrm{w}$-LEDs, especially color rendition and luminous efficiency ${ }^{3-5}$. To date, many important phosphor hosts are built upon the existed structural models, and some typical ones include the garnet-type model, $\mathrm{Si}_{3} \mathrm{~N}_{4}$-type model, apatite-type model, melilite-type model, $\mathrm{A}_{3} \mathrm{MX}$-type model, $\mathrm{UCr}_{4} \mathrm{C}_{4}$-type model, $\beta-\mathrm{K}_{2} \mathrm{SO}_{4}$-type model, and so on ${ }^{-11}$. Among various structure models, garnet-type compounds with a cubic structure has been widely utilized as a host to be applied in illumination and display fields. The garnet host possesses the general formula of $\mathrm{A}_{3} \mathrm{~B}_{2} \mathrm{C}_{3} \mathrm{O}_{12}$ with three different cation cites that gives more flexible compositions through altering the substitution of A, B and C cations ${ }^{6}$. Moreover, the extensive concern about garnettype phosphors puts $\mathrm{Ce}^{3+}$ as a luminous center due to the excellent luminescence properties with broadband excitation in the ultraviolet or blue light region. For instance, the excitation spectrum of commercial $\mathrm{Lu}_{3} \mathrm{Al}_{5} \mathrm{O}_{12}: \mathrm{Ce}^{3+}$ phosphor can match well with the emission of a blue LED chip and one can further easily obtain tunable luminescence in the $\mathrm{Lu}_{3} \mathrm{Al}_{5} \mathrm{O}_{12}: \mathrm{Ce}^{3+}$ via changing the chemical compositions ${ }^{12} . \mathrm{Eu}^{2+}$ acts as the same important activator as $\mathrm{Ce}^{3+}$, while there is rare research about the garnet-type phosphor with $\mathrm{Eu}^{2+}$ as activators, which is ascribed to the reason that it has not a suitable coordination environment for $\mathrm{Eu}^{2+}$ occupying in most garnet-type hosts. Chen et. al. recently reported a blue-emitting phosphor $\mathrm{Lu}_{2} \mathrm{CaMg}_{2} \mathrm{Si}_{3} \mathrm{O}_{12}: \mathrm{Eu}^{2+}$ and no obvious $\mathrm{Eu}^{3+}$ emission exists under $365 \mathrm{~nm}$ excitation ${ }^{13}$. $\mathrm{Y}_{2} \mathrm{Mg}_{2} \mathrm{Al}_{2} \mathrm{Si}_{2} \mathrm{O}_{12}: \mathrm{Eu}^{2+}$ with a tunable emission peak from 436 to $491 \mathrm{~nm}$ were reported by Zhang et al ${ }^{14}$. Besides, it is found that $\mathrm{Eu}^{2+}$ doped $\mathrm{Ca}_{3} \mathrm{Sc}_{2} \mathrm{Si}_{3} \mathrm{O}_{12}$ phosphor exhibits surprising near infrared emission under $520 \mathrm{~nm}$ excitation ${ }^{15}$. It is worthwhile to study $\mathrm{Eu}^{2+}$ doped garnettype phosphor since it will lead to an unexpected luminescence and potential applications.

To obtain optimized luminescence properties, including the position of the excitation and emission along with the spectral bandwidth, the solid solution design based on the equivalent or hetervalent substitution 
strategy acts as one of the most efficient approaches, ${ }^{4,16}$ The ordinarily used design methods mainly contain the cation/anion substitution, cation-pair substitution and the chemical unit cosubstitution ${ }^{17},{ }^{18}$. For example, the red-shift phenomenon was observed in $\mathrm{Ca}_{9} \mathrm{Y}_{(}\left(\mathrm{PO}_{4}\right)_{7}: \mathrm{Eu}^{2+}$ phosphor when the $\mathrm{Sr}^{2+}$ substituted $\mathrm{Ca}^{2+}$ and the $\mathrm{Mg}^{2+}$ substituted $\mathrm{Ca}^{2+}$ and the position of the emission peaks moved toward shorter wavelengths ${ }^{19}$. Liang et al. reported the color-tunable emission in $\mathrm{Sr}_{3} \mathrm{Al}_{2-x} \mathrm{Si}_{x} \mathrm{O}_{5-x} \mathrm{~N}_{x} \mathrm{Cl}_{2}: \mathrm{Eu}^{2+}$ by means of co-substituting $\mathrm{Al}^{3+-} \mathrm{O}^{2-}$ with $\mathrm{Si}^{4+-} \mathrm{N}^{3-20}$. Our group also reported the tunable emission in $\mathrm{Ca}_{9} \mathrm{MgK}\left(\mathrm{PO}_{4}\right)_{7}: \mathrm{Eu}^{2+}$ via the cation substitution with an adjustable chemical environment, and more importantly, and our group firstly summarized the concept of chemical unit cosubstitution with the example of $\mathrm{Ca}_{2}\left(\mathrm{Al}_{1-x} \mathrm{Mg}_{x}\right)\left(\mathrm{Al}_{1-}\right.$ $\left.{ }_{x} \mathrm{Si}_{1+x}\right) \mathrm{O}_{7}: \mathrm{Eu}^{2+}$ phosphors ${ }^{21,22}$.

In this work, $\mathrm{Eu}^{2+}$ doped $\mathrm{Lu}_{2} \mathrm{MgAl}_{4} \mathrm{SiO}_{12}$ phosphors were firstly prepared. The proposed solid solution strategies including cation substitution and chemical unit cosubstitution have been used to realize tunable emission in this system. Besides, the correlation of the crystal structure and luminescence properties of garnet-type phosphor was investigated in detail. To obtain tunable and optimized luminescence properties, the substitution of $\mathrm{Ca}^{2+}$ ions for $\mathrm{Mg}^{2+}$ ions in the $\mathrm{Lu}_{2} \mathrm{MgAl}_{4} \mathrm{SiO}_{12}: \mathrm{Eu}^{2+}$ systems was designed, and its influence on the luminescence and the possible red-shift mechanisms were studied. Moreover, $\left[\mathrm{Ca}^{2+}-\mathrm{Ge}^{4+}\right]$ unit was also introduced into the $\mathrm{Lu}_{2} \mathrm{MgAl}_{4} \mathrm{SiO}_{12}: \mathrm{Eu}^{2+}$ systems to achieve the adjustment of the emission spectra. Commonly, tunable luminescence can be achieved efficiently in $\mathrm{Eu}^{2+}$-activated garnet-type phosphors, which serves a guide in developing novel $\mathrm{Eu}^{2+}$-doped garnet-type phosphors for w-LEDs.

\section{EXPERIMENTAL SECTION}

Materials and Preparation. $\mathrm{Lu}_{2} \mathrm{MgAl}_{4} \mathrm{SiO}_{12}: x \mathrm{Eu}^{2+}$, $\mathrm{Lu}_{2} \mathrm{Mg}_{1-y} \mathrm{Ca}_{y} \mathrm{Al}_{4} \mathrm{SiO}_{12}: 1 \% \mathrm{Eu}^{2+}$ and $\mathrm{Lu}_{2-\mathrm{z}} \mathrm{Ca}_{z} \mathrm{MgAl}_{4-}$ ${ }_{2} \mathrm{Ge}_{z} \mathrm{SiO}_{12}: 1 \% \mathrm{Eu}^{2+}$ powders were prepared by the solidstate reaction method. $\mathrm{Lu}_{2} \mathrm{O}_{3}$ (99.99\%), $\mathrm{MgO}$ (A.R.), $\mathrm{Al}_{2} \mathrm{O}_{3}$ (A.R.), $\mathrm{SiO}_{2}$ (A.R.), $\mathrm{CaCO}_{3}$ (A.R.), $\mathrm{GeO}_{2}$ (A.R.), and $\mathrm{Eu}_{2} \mathrm{O}_{3}$ (99.99\%) were used as raw materials, and a small amount of $\mathrm{H}_{3} \mathrm{BO}_{3}$ (99.99\%) was added as the flux. Stoichiometric amounts of the starting materials were weighted, and then ground together with ethanol as the dispersing agent using an agate mortar and pestle until the mixtures were almost dry (30 min). Then the powder mixtures were sintered at $1400{ }^{\circ} \mathrm{C}$ for $4 \mathrm{~h}$ in a tube furnace under a reducing atmosphere of $\mathrm{N}_{2}-\mathrm{H}_{2}$ (20\%). After firing, the samples were cooled to room temperature in the furnace and were ground again for further characterization.

Characterization. The powder diffraction (XRD) patterns of the samples were measured by using a D8 Advance diffractometer (Bruker Corporation, Germany) with monochromatized $\mathrm{Cu} \mathrm{Ka}$ radiation $(\lambda=1.5406 \AA)$ for crystal structure and phase analysis. And the testing environment of the instrument was operating at room temperature with $40 \mathrm{kV}$ and $40 \mathrm{~mA}$. The step scanning range of $2 \theta$ was from $5^{\circ}$ to $120^{\circ}$ for Rietveld refinements. The step width of $2 \theta$ was $0.013^{\circ}$ with a scanning speed of
$2 \mathrm{~s}$ counting time per step. Rietveld structure refinements were

conducted by using TOPAS 4.2 software. The room temperature photoluminescence excitation (PLE) and PL spectra were measured by using a FLS920 fluorescence spectrophotometer (Edinburgh Instruments Ltd., U.K.). The luminescence decay curves were also collected by a FLS920 at room temperature and excited by a nF900 flash lamp.
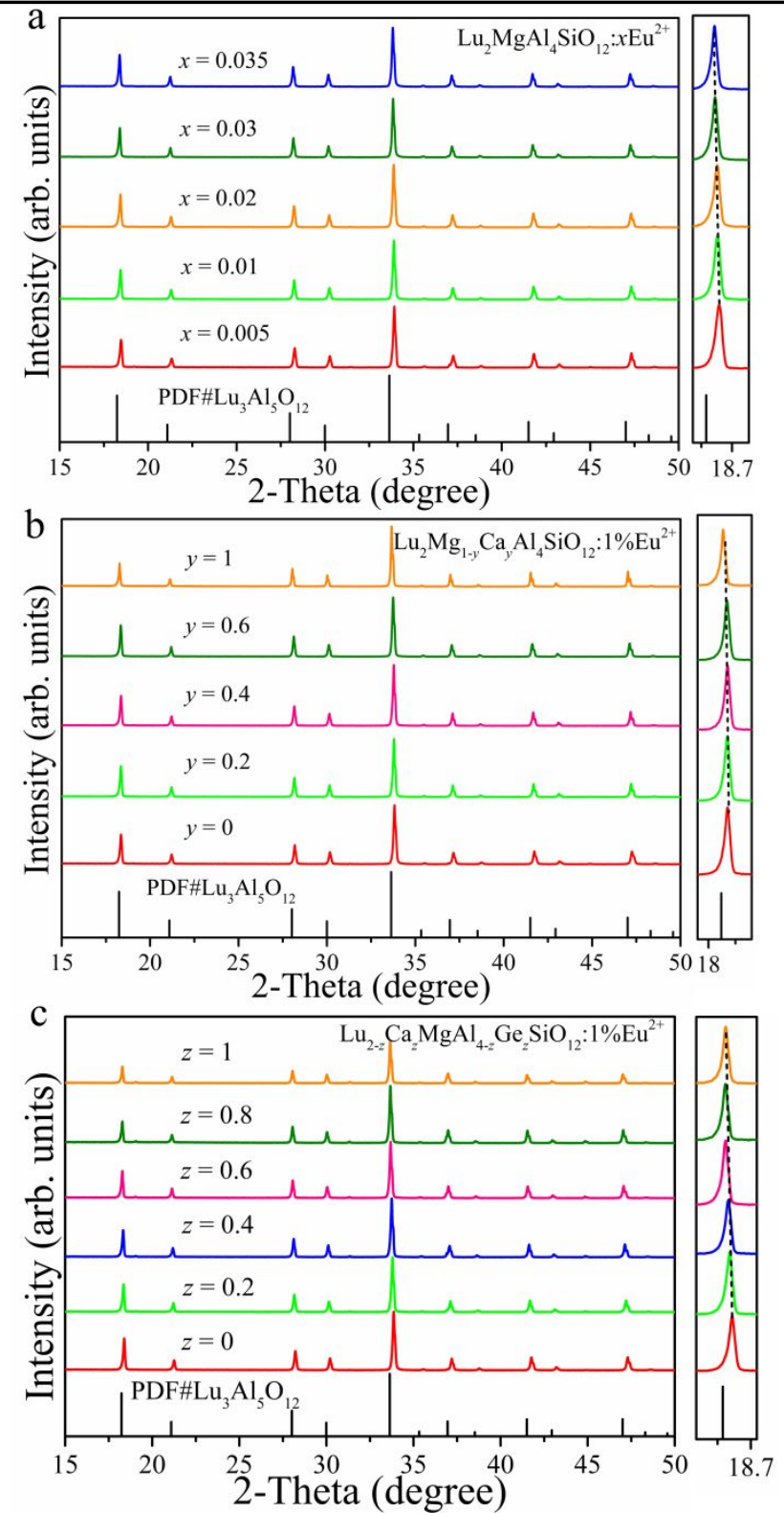

Figure 1. (a) The XRD patterns of the $\mathrm{Lu}_{2} \mathrm{MgAl}_{4} \mathrm{SiO}_{12}: x \mathrm{Eu}^{2+}$ powders with $x=0.005-0.035$. Enlarged XRD patterns show a systematic shift in the peak position of the (211) plane with $\mathrm{Eu}^{2+}$ doping. (b) The XRD patterns of the $\mathrm{Lu}_{2} \mathrm{Mg}_{1-y} \mathrm{Ca}_{y} \mathrm{Al}_{4} \mathrm{SiO}_{12}: 1 \% \mathrm{Eu}^{2+}$ powders with $y=0-1$. Enlarged XRD patterns show a systematic shift in peak position of the (211) plane with $\mathrm{Ca}^{2+}$ doping. (c) The XRD patterns of the $\mathrm{Lu}_{2-z} \mathrm{Ca}_{z} \mathrm{MgAl}_{4-}$ ${ }_{z} \mathrm{SiGe}_{z} \mathrm{O}_{12}: 1 \% \mathrm{Eu}^{2+}$ powders with $z=0-1$. Enlarged XRD 
patterns show a systematic shift in peak position of the (211) plane with $\mathrm{Ca}^{2+}-\mathrm{Ge}^{4+}$ co-doping

\section{RESULTS AND DISCUSSION}

Phase Identification and Crystal Structure Analysis. XRD patterns of as-prepared $\mathrm{Lu}_{2} \mathrm{MgAl}_{4} \mathrm{SiO}_{12}: x \mathrm{Eu}^{2+}, \mathrm{Lu}_{2} \mathrm{Mg}_{1-y} \mathrm{Ca}_{y} \mathrm{Al}_{4} \mathrm{SiO}_{12}: 1 \% \mathrm{Eu}^{2+}$ and $\mathrm{Lu}_{2-\mathrm{z}} \mathrm{Ca}_{\mathrm{z}} \mathrm{MgAl}_{4-\mathrm{z}} \mathrm{GezSiO}_{12}: 1 \% \mathrm{Eu}^{2+}$ samples are shown in Figure 1. Obviously, the XRD patterns of these samples are in good agreement with the standard card (PDF \#731368) pattern of $\mathrm{Lu}_{3} \mathrm{Al}_{5} \mathrm{O}_{12}$ from Figure 1a, suggesting that the doping of $\mathrm{Eu}^{2+}$ does not influence the phase purity and $\mathrm{Eu}^{2+}$ ions are doped in the host lattice. It is noticed that the XRD diffraction peaks of the enlarged XRD patterns systematically shift towards lower angles as seen for the peak position of the (211) plane when $x$ increased, indicating a lattice expansion due to the replacement of the small $\mathrm{Lu}^{3+}(\mathrm{CN}=8, \mathrm{R}=0.977 \AA ; \mathrm{CN}$ stands for coordination number, $\mathrm{R}$ denotes ionic radius, hereafter) and $\mathrm{Mg}^{2+}(\mathrm{CN}=8, \mathrm{R}=0.89 \AA)$ with the big $\mathrm{Eu}^{2+}(\mathrm{CN}=8$, $\mathrm{R}=1.25 \AA$ ). In addition, Rietveld refinement was performed by using TOPAS 4.2 for the $\mathrm{Lu}_{2} \mathrm{MgAl}_{4} \mathrm{SiO}_{12}: 1 \% \mathrm{Eu}^{2+}$ samples. The cell parameters are a $=\mathrm{b}=\mathrm{c}=11.8574$ (1) $\AA$ and cell volume is 1667.14 (4) $\AA$. According to the refinement result from Figure 2a, almost all of peaks of the studied samples were indexed to a cubic cell $(I a-3 d)$ with parameters close to $\mathrm{Lu}_{3} \mathrm{Al}_{5} \mathrm{O}_{12}$ besides small impurity peaks of the $\mathrm{Mg}_{2} \mathrm{SiO}_{4}$ phase. Based on the previous papers, the trace impurity $\mathrm{Mg}_{2} \mathrm{SiO}_{4}$ has no effect on the luminescence of $\mathrm{Lu}_{2} \mathrm{MgAl}_{4} \mathrm{SiO}_{12}: x \mathrm{Eu}^{2+}$ because $\mathrm{Eu}$ doped $\mathrm{Mg}_{2} \mathrm{SiO}_{4}$ cannot retain the divalent state and show emission $^{23}$. The results of the Rietveld refinement displayed that $\mathrm{Eu}^{2+}$ occupied the crystallographic site of the $\mathrm{Lu}^{3+}$ and $\mathrm{Mg}^{2+}$.

It is obvious that the XRD patterns of the $\mathrm{Lu}_{2} \mathrm{Mg}_{1}$ ${ }_{y} \mathrm{Ca}_{y} \mathrm{Al}_{4} \mathrm{SiO}_{12}: 1 \% \mathrm{Eu}^{2+}$ matched well with the standard card pattern of $\mathrm{Lu}_{3} \mathrm{Al}_{5} \mathrm{O}_{12}$ from Figure $1 \mathrm{~b}$, indicating that the replacement of $\mathrm{Ca}^{2+}$ with $\mathrm{Mg}^{2+}$ has no influence on the crystal structure. Since the big ionic radius $\mathrm{Ca}^{2+}$ substitutes for the small ionic radius $\mathrm{Mg}^{2+}$ causing lattice expansion, enlarged XRD patterns show a simultaneous shift toward lower angles in peak position of the (211) plane with the $\mathrm{Ca}^{2+}$ doping. The result of the Rietveld refinement shown in Figure $2 \mathrm{~b}$ displays that the phase of the as-prepared sample $\mathrm{Lu}_{2} \mathrm{CaAl}_{4} \mathrm{SiO}_{12}: 1 \% \mathrm{Eu}^{2+}$ was pure. Figure 1c presents the XRD patterns of the products with $\mathrm{Ca}^{2+}-\mathrm{Ge}^{4+}$ co-doping in the $\mathrm{Lu}_{2} \mathrm{MgAl}_{4} \mathrm{SiO}_{12}: \mathrm{Eu}^{2+}$ system. All the diffraction peaks of the samples with $\left[\mathrm{Ca}^{2+}-\mathrm{Ge}^{4+}\right]$ co-doping can be ascribed to a pure cubic $\mathrm{Lu}_{3} \mathrm{Al}_{5} \mathrm{O}_{12}$ phase and the diffraction peak of the (211) plane also gradually shifted to lower angles with the doping of $\mathrm{Ca}$ and $\mathrm{Ge}$ ions, which proved the successful doping of the $\left[\mathrm{Ca}^{2+}-\mathrm{Ge}^{4+}\right]$ unit co-substitution process.

Figure 3 summarizes the different crystal structure evolution routes from the $\mathrm{Lu}_{2} \mathrm{MgAl}_{4} \mathrm{SiO}_{12}$ matrix to the $\mathrm{Lu}_{2} \mathrm{MgAl}_{4} \mathrm{SiO}_{12}: \mathrm{Eu}^{2+}$ phosphor, $\mathrm{Lu}_{2} \mathrm{CaAl}_{4} \mathrm{SiO}_{12}: \mathrm{Eu}^{2+}$ phosphor and $\mathrm{LuCaMgAl}_{3} \mathrm{GeSiO}_{12}: \mathrm{Eu}^{2+}$ phosphor via the substitution strategy. Apparently, some ions occupy the octahedral site, $\mathrm{Al} 2$ and $\mathrm{Si}$ form the $\mathrm{Al} 2 / \mathrm{SiO}_{4}$ tetrahedron, while $\mathrm{Lu} / \mathrm{Mg}$ occupy the interstitial site of $\mathrm{Al}_{1} \mathrm{O}_{6}$ connecting with $\mathrm{Al} 2 / \mathrm{SiO}_{4}$ by corner sharing. With the $\mathrm{Ca}^{2+}$ or $\left[\mathrm{Ca}^{2+}-\mathrm{Ge}^{4+}\right]$ doping, the crystal coordination environment
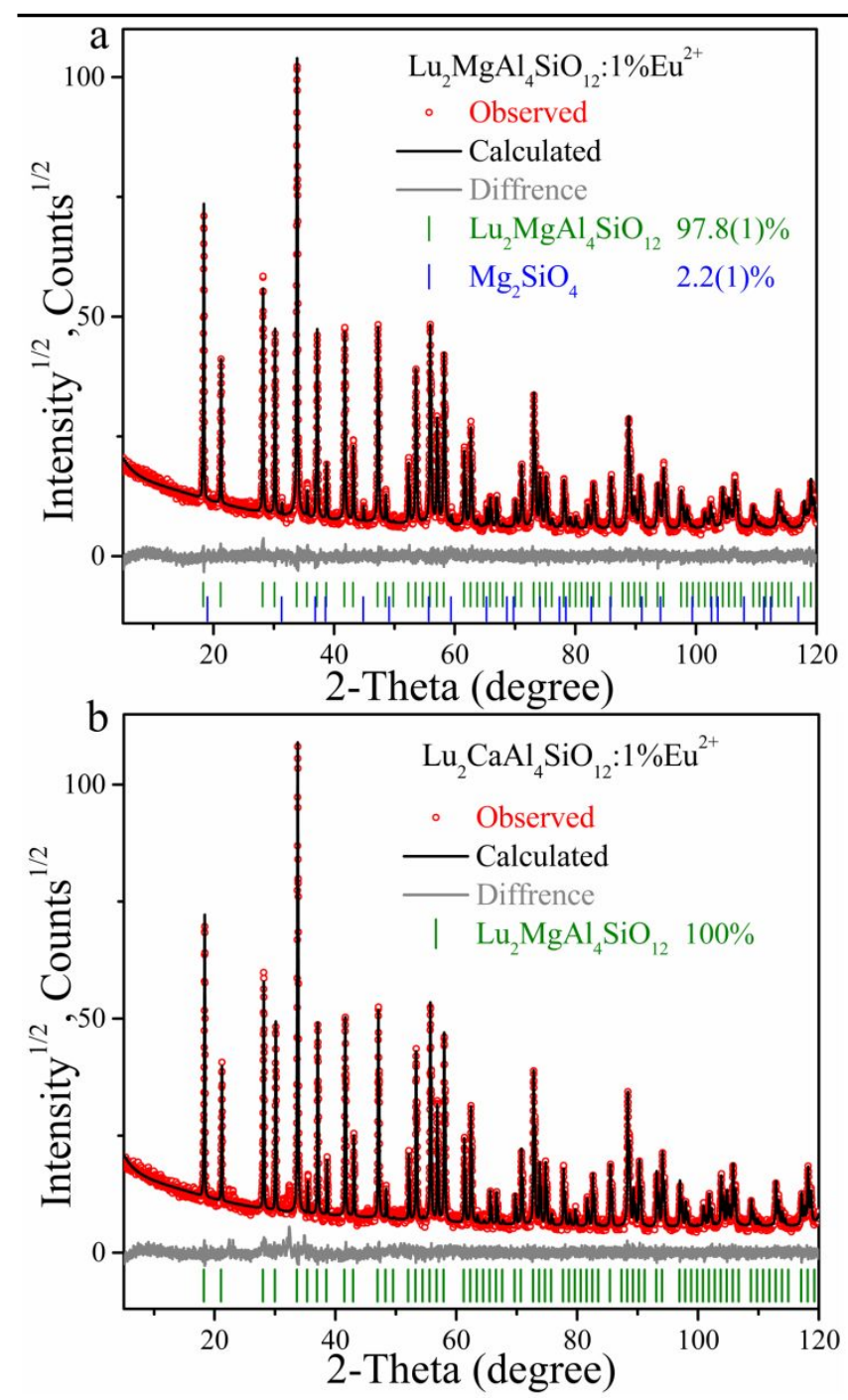

Figure 2. Rietveld refinement XRD patterns of the (a) $\mathrm{Lu}_{2} \mathrm{MgAl}_{4} \mathrm{SiO}_{12}: 1 \% \mathrm{Eu}^{2+}$ and (b) $\mathrm{Lu}_{2} \mathrm{CaAl}_{4} \mathrm{SiO}_{12}: 1 \% \mathrm{Eu}^{2+}$.

has been changed. which may cause the variation of the luminescent properties.

Photoluminescence Properties of $\mathbf{L u}_{2} \mathbf{M g A l}_{4} \mathbf{S i O}_{12}: \mathbf{E u}^{2+}$. The room temperature excitation and emission spectrum of $\mathrm{Lu}_{2} \mathrm{MgAl}_{4} \mathrm{SiO}_{12}$ doped with $1 \% \mathrm{Eu}^{2+}$ are shown in Figure $4 \mathrm{a}$, along with the inset actual photograph of the sample under $365 \mathrm{~nm}$ UV lamp irradiation. It exhibited a broad excitation band covering a spectral range of $250-450 \mathrm{~nm}$, which means that it can match well with the n-UV LED chips, which is attributed to the electronic transitions of $\mathrm{Eu}^{2+}$ from its $4 \mathrm{f}$ ground state to its field-splitting levels of the $5 \mathrm{~d}$ state. The PL spectrum of $\mathrm{Lu}_{2} \mathrm{MgAl}_{4} \mathrm{SiO}_{12}: 1 \% \mathrm{Eu}^{2+}$ consisted of one broad nonsymmetrical band with a peak at about $463 \mathrm{~nm}$ under the excitation of $365 \mathrm{~nm}$ UV radiation and a tail at the long-wavelength side, indicated that there exist at least two emission centers. The broad emission band can be deconvoluted into two sub-Gaussian components suggesting 


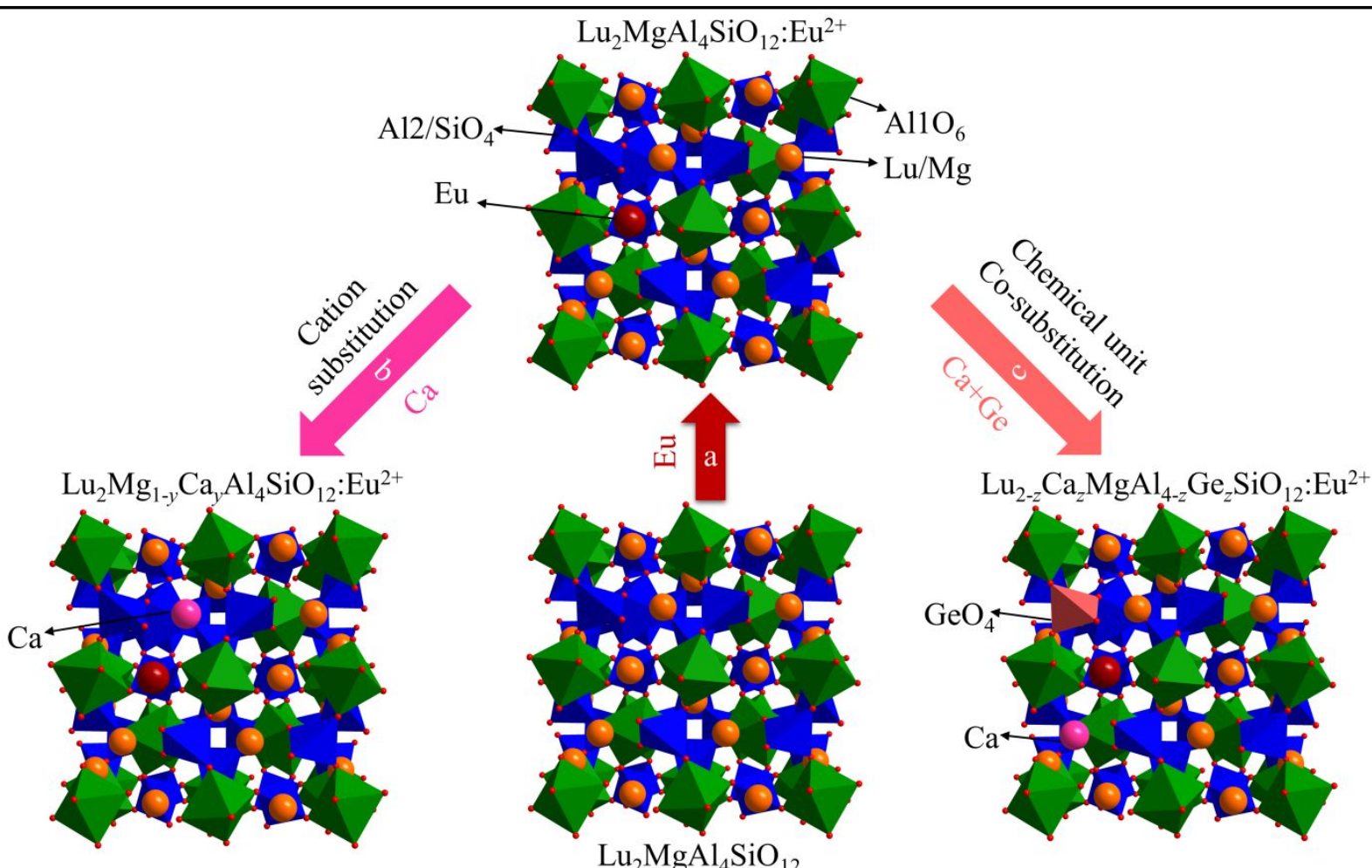

Figure 3. The crystal structure evolution from the $\mathrm{Lu}_{2} \mathrm{MgAl}_{4} \mathrm{SiO}_{12}$ matrix to the $\mathrm{Lu}_{2} \mathrm{MgAl}_{4} \mathrm{SiO}_{12}: \mathrm{Eu}^{2+}$ by doping Eu${ }^{2+}$ ions, $\mathrm{Lu}_{2} \mathrm{Mg}_{1-y} \mathrm{Ca}_{y} \mathrm{Al}_{4} \mathrm{SiO}_{12}: \mathrm{Eu}^{2+}$ by cation substitution of replacing $\mathrm{Mg}^{2+}$ with a bigger cation $\mathrm{Ca}^{2+}, \mathrm{Lu}_{2-z} \mathrm{Ca}_{z} \mathrm{MgAl}_{4-z} \mathrm{SiGe}_{z} \mathrm{O}_{12}: \mathrm{Eu}^{2+}$ by chemical unit co-substitution of replacing $\left[\mathrm{Lu}^{3+}-\mathrm{Al}^{3+}\right]$ with $\left[\mathrm{Ca}^{2+}-\mathrm{Ge}^{4+}\right]$.

the different occupancy of $\mathrm{Eu}^{2+}$, peaking at $\sim 454 \mathrm{~nm}$ $\left(22026 \mathrm{~cm}^{-1}\right)$ and $\sim 500 \mathrm{~nm}\left(20000 \mathrm{~cm}^{-1}\right)$ as shown in Figure $4 \mathrm{~b}$.

To further know the origin of the luminescence center $\mathrm{Eu}^{2+}$ in the $\mathrm{Lu}_{2} \mathrm{MgAl}_{4} \mathrm{SiO}_{12}$ phosphor, the empirical Van Uitert equation was used to analyses the results of the emission spectra. The equation is given as follows according to the previous report ${ }^{24,25}$ :

$E=Q\left[1-\left(\frac{V}{4}\right)^{\frac{1}{V}} 10^{-\frac{n \times E a \times r}{80}}\right]$

where $E$ is the position of the $\mathrm{Eu}^{2+}$ emission peak $\left(\mathrm{cm}^{-1}\right)$, $Q$ is the position in energy for the lower d-band edge of the free $\mathrm{Eu}^{2+}$ ion $\left(34000 \mathrm{~cm}^{-1}\right.$ for $\left.\mathrm{Eu}^{2+}\right), V$ is the valence of the $\mathrm{Eu}^{2+}$ ion ( $V$ value is 2), $\mathrm{n}$ is the number of anions in the immediate shell about the $\mathrm{Eu}^{2+}$ ion, $E_{a}$ is the electron affinity of the atoms of the anions (it is a constant for the same host), $R$ is radius of the cation replaced by the $\mathrm{Eu}^{2+}$ ion $(\AA)^{14,26}$. It is the same coordination number for $\mathrm{Lu}$ and $\mathrm{Mg}$ in $\mathrm{Eu}^{2+}$ doped $\mathrm{Lu}_{2} \mathrm{MgAl}_{4} \mathrm{SiO}_{12}$ phosphor. Based on the above analysis, it is obvious that $E$ is proportional to $R$. Considering the radius of $\mathrm{Lu}$ larger than $\mathrm{Mg}$ in $\mathrm{Lu}_{2} \mathrm{MgAl}_{4} \mathrm{SiO}_{12}$, the emission band peaked at $454 \mathrm{~nm}$ belongs to $\mathrm{Eu}^{2+}$ occupying the $\mathrm{Lu}$ site and the emission band peaked at $500 \mathrm{~nm}$ is ascribed to that $\mathrm{Eu}^{2+}$ occupying the Mg site. The measured emission spectra have emission peaks centered at $463 \mathrm{~nm}$ near $454 \mathrm{~nm}$, which can draw a conclusion that the $\mathrm{Eu}^{2+}$ preferentially occupies the 8-fold coordinated $\mathrm{Lu}$ sites in the $\mathrm{Lu}_{2} \mathrm{MgAl}_{4} \mathrm{SiO}_{12}$ structure. Figure $4 \mathrm{c}$ shows the decay curves of the $\mathrm{Lu}_{2} \mathrm{MgAl}_{4} \mathrm{SiO}_{12}: 1 \% \mathrm{Eu}^{2+}$ at room temperature

monitored under excitation at $365 \mathrm{~nm}$ and emission at $463 \mathrm{~nm}$. This fluorescence decay curve can be well-fitted by a second-order exponential function ${ }^{24}$

$I(t)=\mathrm{A}_{1} \exp \left(-t / \tau_{1}\right)+\mathrm{A}_{2} \exp \left(-t / \tau_{2}\right)$

where $I(t)$ is the luminescence intensity; $\mathrm{A}_{1}$ and $\mathrm{A}_{2}$ are constants; $t$ is time; and $\tau_{1}$ and $\tau_{2}$ are the lifetimes for the exponential components. Furthermore, the average decay time value $\left(\tau_{a v}\right)$ was calculated using the following equation ${ }^{19}$

$\tau_{a v}=\left(\mathrm{A}_{1} \tau_{1}^{2}+\mathrm{A}_{2} \tau_{2}^{2}\right) /\left(\mathrm{A}_{1} \tau_{1}+\mathrm{A}_{2} \tau_{2}\right)$

By calculating, the average lifetime is determined as 0.881 $\mu \mathrm{s}$, and the second-order exponential behavior also verifies the existence of two different emission centers. Under $365 \mathrm{~nm}$ excitation, the PL spectra of the samples $\mathrm{Lu}_{2} \mathrm{MgAl}_{4} \mathrm{SiO}_{12}: x \mathrm{Eu}^{2+}$ with $x$ changing from $0.5 \%$ to $3.5 \%$, were depicted in Figure 5a. Obviously, the emission intensity of the samples reached its maximum when $x$ was $1 \%$, and then the concentration quenching effect results in the decline of the emission intensity. From the normalized PL spectra of the $\mathrm{Lu}_{2} \mathrm{MgAl}_{4} \mathrm{SiO}_{12}: x \mathrm{Eu}^{2+}$ phosphors as displayed in Figure 5b, a $15 \mathrm{~nm}$ red-shift of emission peak position was observed meaning the possibility of a spectral peak regulating by controlling the $\mathrm{Eu}^{2+}$ concentration, which may attribute to the increase in crystal field splitting. Meanwhile, the inset shows the CIE chromaticity coordinates of the phosphors from the blue region shifting toward the blue-green region with an increasing $x$ as shown in Figure $5 b$.

Photoluminescence tuning via Cation
Substitution.




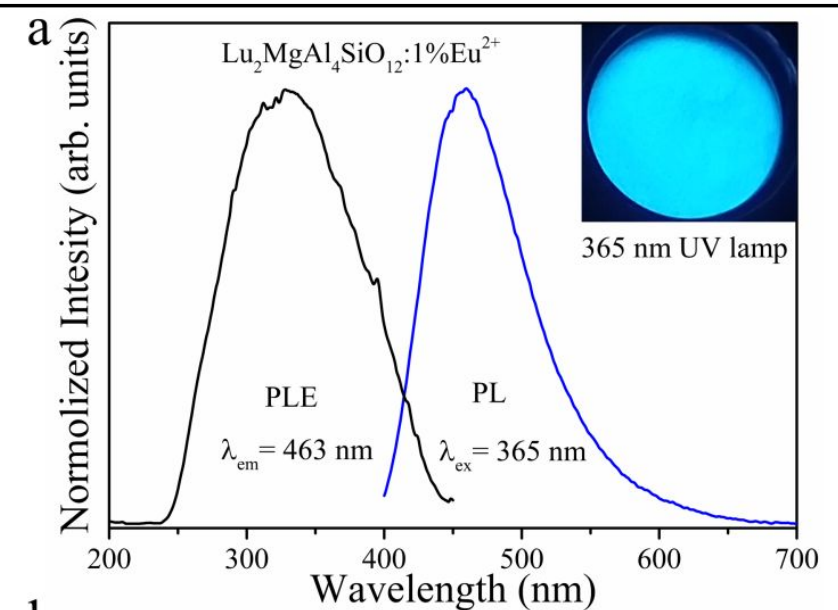

b
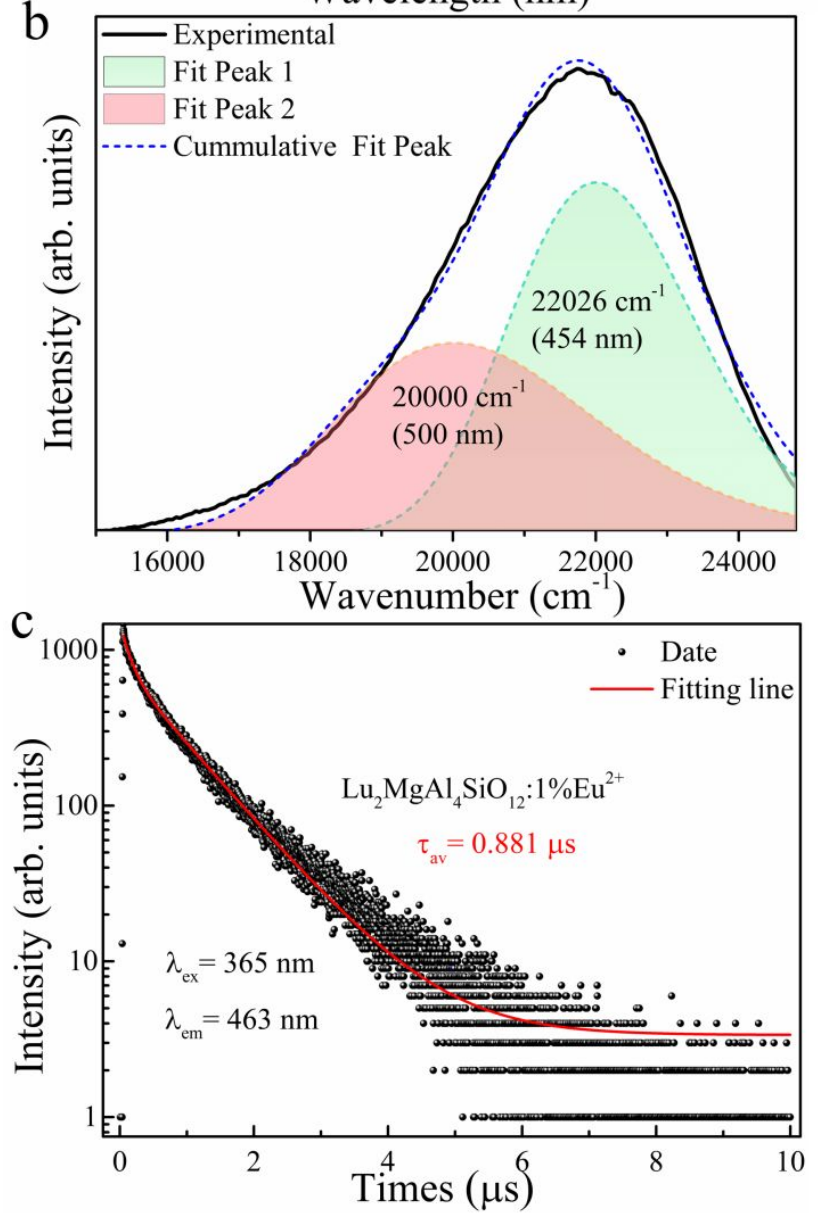

Figure 4. (a) PLE and PL spectra of the $\mathrm{Lu}_{2} \mathrm{MgAl}_{4} \mathrm{SiO}_{12}: 1 \% \mathrm{Eu}^{2+}$ phosphors monitored at room temperature, and the inset shows the phosphor images under $365 \mathrm{~nm}$ UV light. (b) Gaussian fitting results of PL bands for the $\mathrm{Lu}_{2} \mathrm{MgAl}_{4} \mathrm{SiO}_{12}: 1 \% \mathrm{Eu}^{2+}$, (c) Decay curves of the $463 \mathrm{~nm}$ emission and excited $365 \mathrm{~nm}$ from the $\mathrm{Lu}_{2} \mathrm{MgAl}_{4} \mathrm{SiO}_{12}: 1 \% \mathrm{Eu}^{2+}$ at room temperature.

By means of cation substituting in $\mathrm{Lu}_{2} \mathrm{MgAl}_{4} \mathrm{SiO}_{12}: \mathrm{Eu}^{2+}$ phosphor, the emission color of the phosphors can be tuned due to the changing crystal field environment of the doped activators. $\mathrm{Lu}_{2} \mathrm{MgAl}_{4} \mathrm{SiO}_{12}$ is isotypic to $\mathrm{Lu}_{2} \mathrm{CaAl}_{4} \mathrm{SiO}_{12}$, and therefore it can form a complete solid solution by cation substituting due to the small gap in the ion radius between the $\mathrm{Ca}^{2+}$ and $\mathrm{Mg}^{2+}$. The normalized emission spectra of the phosphors $\mathrm{Lu}_{2} \mathrm{Mg}_{1-}$ ${ }_{y} \mathrm{Ca}_{y} \mathrm{Al}_{4} \mathrm{SiO}_{12}: 1 \% \mathrm{Eu}^{2+}$ were recorded in Figure $6 \mathrm{a}$ under monitoring at $365 \mathrm{~nm}$ and the value of $y$ in the solid solution was varied from 0 to 1 . It is obvious that the emission peak shape and position vary with the $\mathrm{Ca}^{2+}$ concentration. The change of the emission peak shape maybe come from part of the $\mathrm{Eu}^{2+}$ at the position of the $\mathrm{Ca}^{2+}$ sites. The sample with $y=0$ exhibits a wide asymmetric emission band with one peak at $463 \mathrm{~nm}$ without any characteristic emission of $\mathrm{Eu}^{3+}$. However, the broadband emission peak shifts to the long wavelength and reaches $488 \mathrm{~nm}$ along with the appearance of $591 \mathrm{~nm}$ and $612 \mathrm{~nm}$ emission peaks of $\mathrm{Eu}^{3+}$ when $y=0.6$, indicated that the crystal rigid of the $\mathrm{Eu}^{2+}$ local coordination environment decreasing at high $\mathrm{Ca}^{2+}$ content, and it also leads to the oxidation process from $\mathrm{Eu}^{2+}$ to $\mathrm{Eu}^{3+}$. The emission peak gradually redshifted with increasing in the $y$ value, eventually to $503 \mathrm{~nm}$ when the $\mathrm{Ca}^{2+}$ ion absolutely replaced the $\mathrm{Mg}^{2+}$ ion $(y=1)$.
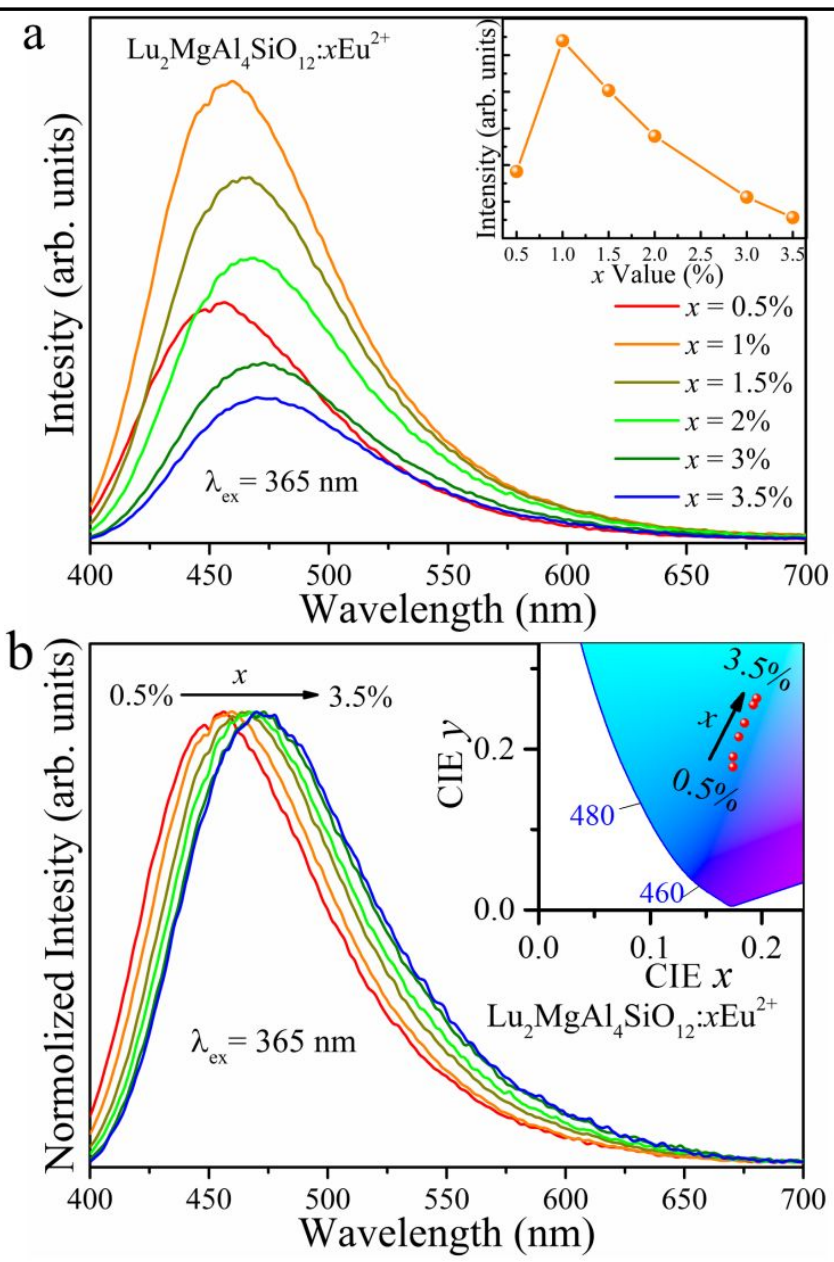

Figure 5. (a) PL spectra of the $\mathrm{Lu}_{2} \mathrm{MgAl}_{4} \mathrm{SiO}_{12}: x \mathrm{Eu}^{2+}$ phosphors monitored at $365 \mathrm{~nm}$ and the inset shows the PL maximum intensity of the $\mathrm{Lu}_{2} \mathrm{MgAl}_{4} \mathrm{SiO}_{12}: x \mathrm{Eu}^{2+}$. (b) Normalized PL spectra of the $\mathrm{Lu}_{2} \mathrm{MgAl}_{4} \mathrm{SiO}_{12}: x \mathrm{Eu}^{2+}$ phosphors monitored at $365 \mathrm{~nm}$ and the inset shows the CIE chromaticity coordinates. 

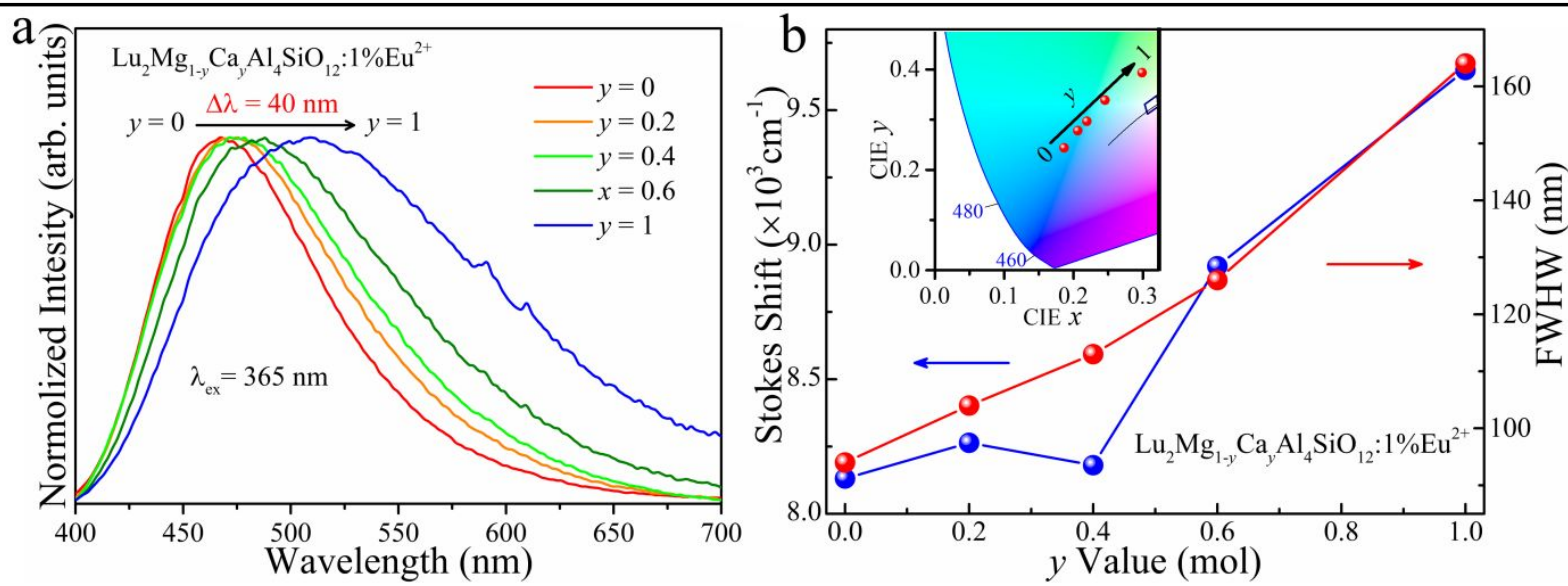

c

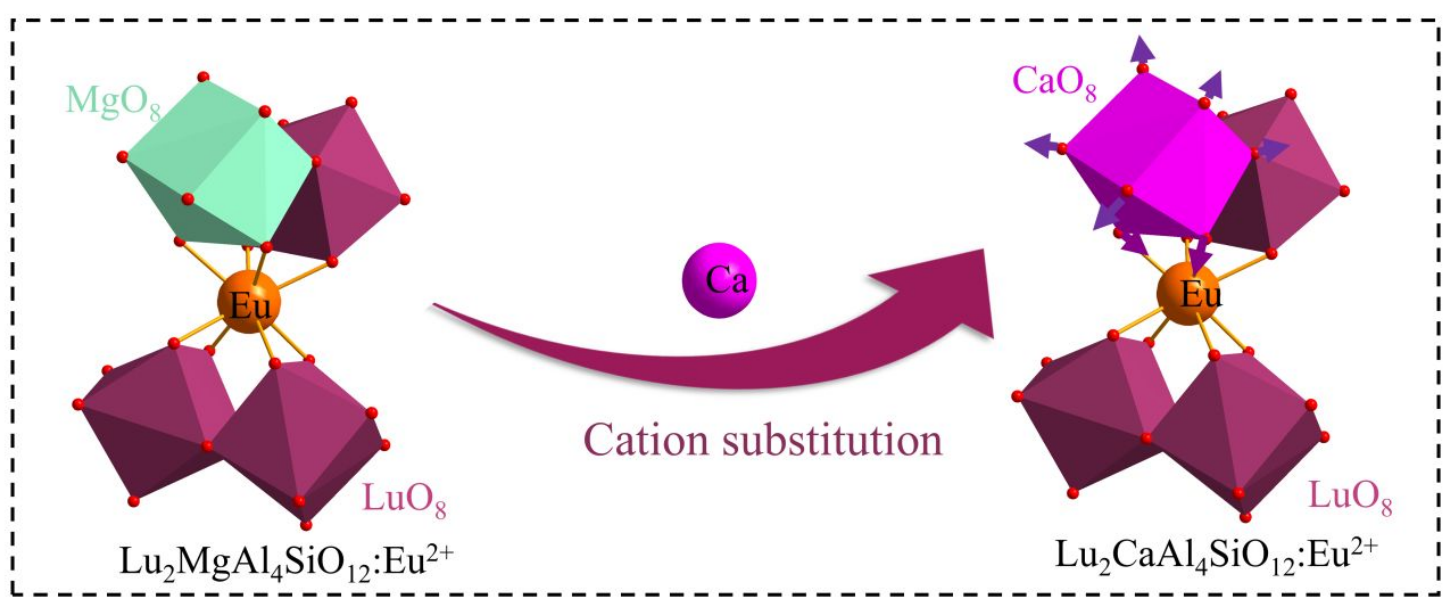

Figure 6. Normalized PL spectra of $\mathrm{Lu}_{2} \mathrm{Mg}_{1-y} \mathrm{Ca}_{y} \mathrm{Al}_{4} \mathrm{SiO}_{12}: 1 \% \mathrm{Eu}^{2+}$ phosphors monitored at $365 \mathrm{~nm}$. (b) Stokes shift and FWHM values of the $\mathrm{Lu}_{2} \mathrm{Mg}_{1-y} \mathrm{Ca}_{y} \mathrm{Al}_{4} \mathrm{SiO}_{12}: 1 \% \mathrm{Eu}^{2+}$ phosphors and the inset show the CIE chromaticity coordinates. (c) Shrinkage mechanism of the $\mathrm{EuO}_{8}$ polyhedron with $\mathrm{Ca}^{2+}$ substituting $\mathrm{Mg}^{2+}$ in $\mathrm{Lu}_{2} \mathrm{Mg}_{1-y} \mathrm{Ca}_{y} \mathrm{Al}_{4} \mathrm{SiO}_{12}: \mathrm{Eu}^{2+}$.

As shown in the inset of Figure 6b, CIE chromaticity coordinates of the $\mathrm{Lu}_{2} \mathrm{Mg}_{1-y} \mathrm{Ca}_{4} \mathrm{Al}_{4} \mathrm{SiO}_{12}: 1 \% \mathrm{Eu}^{2+}$ samples shift from $(0.186,0.244)$ toward $(0.299,0.394)$ with the increasing amount of $y$. It is well known that the Stokes shift makes a great difference to the position of the emission peak, so that the increasing of the Stokes shift could explain the redshift phenomenon of the emission spectra. Correspondingly, the Stokes shift obtained by considering the difference between emission and excitation spectra and the full width at half-maxima (FWHM) of the emission spectra are displayed in Figure 6b. Overall, the Stokes shift of the $\mathrm{Lu}_{2} \mathrm{Mg}_{1}$. ${ }_{y} \mathrm{Ca}_{y} \mathrm{Al}_{4} \mathrm{SiO}_{12}: 1 \% \mathrm{Eu}^{2+}$ phosphors raised along with the $\mathrm{y}$ value increasing from $y=0$ to 1 , which agree well with the redshift phenomenon. Meanwhile, the increase of the $\mathrm{Ca}^{2+}$ content also led to the emission band of the $\mathrm{Lu}_{2} \mathrm{Mg}_{1-}$ ${ }_{y} \mathrm{Ca}_{y} \mathrm{Al}_{4} \mathrm{SiO}_{12}: 1 \% \mathrm{Eu}^{2+}$ phosphors broadening as displayed in Figure 6b, which is propitious to improve the color rendering index. The crystal field splitting of the $\mathrm{Eu}^{2+} 5 \mathrm{~d}$ levels can also affect the emission peak moving due to affecting the position of the lowest $5 \mathrm{~d}$ levels. And the crystal field splitting energy is based on the equation as follow $24,27,28$

$D_{q}=\frac{z e^{2} r^{4}}{6 R^{5}}$

In the above equation, $D_{q}$ is the crystal field splitting energy, $R$ represents the distance between the central ion
$\mathrm{Eu}^{2+}$ and its ligands, $z$ represents the anion charge, $e$ is the charge of the electron, and $r$ is the radius of the $d$ wave function. If the value of $D_{q}$ is small, the emission peak will locate at high energy direction. Contrarily, the large value of $D_{q}$ makes the emission peak to locate at low energy direction ${ }^{28}$. According to the refinements results, the bond length of $\mathrm{Lu} / \mathrm{Mg} / \mathrm{Eu}-\mathrm{O}$ in $y=0$ sample is smaller than $\mathrm{Lu} / \mathrm{Ca} / \mathrm{Eu}-\mathrm{O}$ in $y=1$ sample, indicated that the $\mathrm{Ca}^{2+}$ replacing $\mathrm{Mg}^{2+}$ may expand the average $\mathrm{Eu}-\mathrm{O}$ bond length. Considering the $Z, e$, and $r$ hold the line in the same host, it means that the crystal field splitting energy will decrease with the increasing $\mathrm{Ca}^{2+}$ amounts. Surprisingly, it contradicts with the experimental result of the emission spectra that redshifted as shown in Figure 6a.

Apart from the Eu-O bond length, the crystal field strength is also dependent on the local symmetry of the $\mathrm{Eu}^{2+}$ sites. In addition, the substitution of $\mathrm{Mg}^{2+}$ for $\mathrm{Ca}^{2+}$ would change the symmetry of the $\mathrm{Lu}_{2} \mathrm{MgAl}_{4} \mathrm{SiO}_{12}: \mathrm{Eu}^{2+}$ crystal structure, and therefore it may strengthen or weaken the crystal field splitting of the $\mathrm{Eu}^{2+} 5 \mathrm{~d}$ levels. The polyhedron distortion index $(D)$ influences the symmetry of the crystal structure, and it can be calculated by ${ }^{26,29,30}$

$D=\frac{1}{n} \sum_{i=1}^{n} \frac{\left|l_{i}-l_{a v}\right|}{l_{a v}}$

where $l_{i}$ is the distance from the central atom Eu to the $i$ th coordinating atom and $l_{a v}$ is the average bond length. 

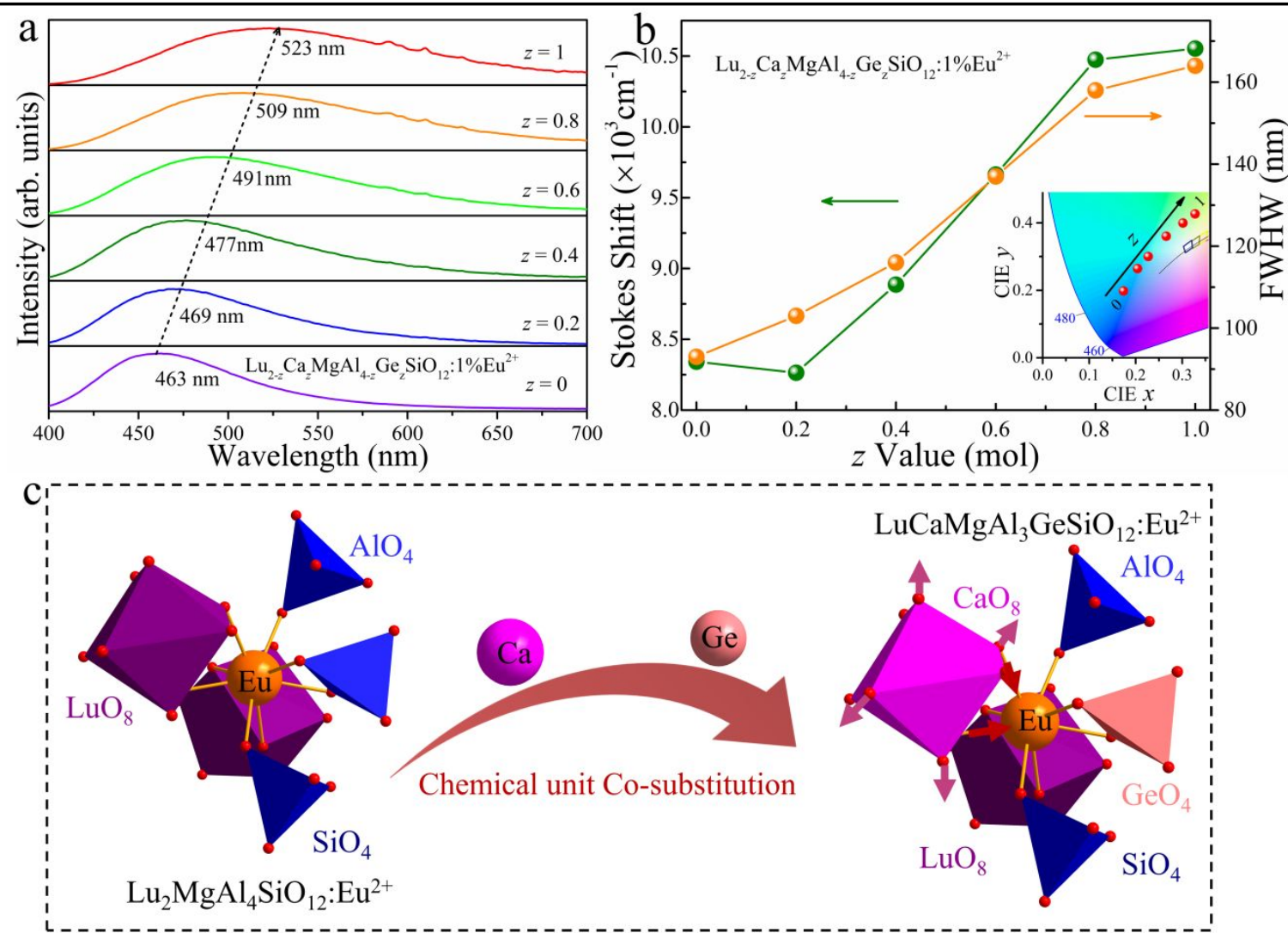

Figure 7. (a) PL spectra of the $\mathrm{Lu}_{2-z} \mathrm{CazMgAl}_{4-\mathrm{Z}} \mathrm{Ge}_{z} \mathrm{SiO}_{12}: 1 \% \mathrm{Eu}^{2+}$ phosphors monitored at $365 \mathrm{~nm}$. (b) Stokes shift and FWHM values of $\mathrm{Lu}_{2-z} \mathrm{CazMgAl}_{4-\mathrm{z}} \mathrm{Ge}_{z} \mathrm{SiO}_{12}: 1 \% \mathrm{Eu}^{2+}$ phosphors and the inset show the CIE chromaticity coordinates. (c) Shrinkage mechanism of the $\mathrm{EuO}_{8}$ polyhedron with $\mathrm{Ca}^{2+} \mathrm{Ge}^{4+}$ substituting $\mathrm{Lu}^{3+}-\mathrm{Al}^{3+}$ in the $\mathrm{Lu}_{2-\mathrm{z}} \mathrm{CazMgAl}_{4^{-}}$ ${ }_{z} \mathrm{Ge}_{z} \mathrm{SiO}_{12}: 1 \% \mathrm{Eu}^{2+}$.

Based on the dates of the $\mathrm{Eu}^{2+-} \mathrm{O}^{2-}$ bond length from the refinements results, the polyhedron distortion index of the $\mathrm{EuO}_{8}$ polyhedron enlarged from $D=2.38 \%$ is inversely proportional to $R$. to $D=2.88 \%$ along with $\mathrm{Ca}^{2+}$ replacing $\mathrm{Mg}^{2+}$, also decreasing the lattice symmetry of the $\mathrm{Eu}^{2+}$ sites. As a result, the emission band broadened and the emission peaks generated a redshift in the $\mathrm{Lu}_{2} \mathrm{Mg}_{1-y} \mathrm{Ca}_{y} \mathrm{Al}_{4} \mathrm{SiO}_{12}: 1 \% \mathrm{Eu}^{2+}$ system. Previous work has displayed that the bigger the polyhedral distortion index, the bigger the crystal field splitting ${ }^{9,29}$. Hence, the lattice symmetry of the $\mathrm{Eu}^{2+}$ sites degrading may provide a substantially contribution to the enhancement of the crystal field splitting than the distance between the $\mathrm{Eu}^{2+}$ and $\mathrm{O}^{2-}$ in this system, which consequently brought about the redshift of the emission spectrum.

From the point of the local coordination environment around the $\mathrm{Eu}^{2+}$ ion in this compound, the $\mathrm{EuO}_{8}$ polyhedron has joint edges with the $(\mathrm{Lu} / \mathrm{Mg}) \mathrm{O}_{8}$ polyhedra, the systematic model exhibited the shrinkage of the $\mathrm{EuO}_{8}$ polyhedron with a deterioration in the structure symmetry of the Eu dodecahedron owing to the bigger $\mathrm{CaO}_{8}$ polyhedron substituting the smaller $\mathrm{MgO}_{8}$ polyhedron in the second sphere, as illustrated in Figure 6c. Consequently, emission spectra were simultaneously broadened and red-shifted following the increasing $y$ value.

\section{Photoluminescence tuning via Chemical Unit Co-} substitution.
As another photoluminescence tuning strategy for the $\mathrm{Lu}_{2} \mathrm{MgAl}_{4} \mathrm{SiO}_{12}: \mathrm{Eu}^{2+}$ sample, the chemical unit cosubstitution of $\left[\mathrm{Ca}^{2+}-\mathrm{Ge}^{4+}\right]$ for $\left[\mathrm{Lu}^{3+}-\mathrm{Al}^{3+}\right]$ was used to change the crystal lattice environment around the $\mathrm{Eu}^{2+}$ in a possible wider range. Under an excitation wavelength of $365 \mathrm{~nm}$, the normalized emission spectrum presented an obvious redshift phenomenon with the increasing concentration of the $\left[\mathrm{Ca}^{2+}-\mathrm{Ge}^{4+}\right]$ as shown in Figure $7 \mathrm{a}$. The maximum peak in the PL spectra moved from $463 \mathrm{~nm}$ for $z=0$ to $523 \mathrm{~nm}$ for $z=1$, which may be caused by the improvement of the crystal field splitting energy. Besides, the CIE of the $\mathrm{Lu}_{2-z} \mathrm{Ca}_{z} \mathrm{MgAl}_{4-z} \mathrm{Ge}_{z} \mathrm{SiO}_{12}: 1 \% \mathrm{Eu}^{2+}$ phosphors gradually shifted from the blue region $(0.186,0.244)$ to the green region $(0.328,0.457)$ through increasing the $\left[\mathrm{Ca}^{2+}-\mathrm{Ge}^{4+}\right]$ doping content. However, the addition of $\left[\mathrm{Ca}^{2+}-\mathrm{Ge}^{4+}\right]$ in the $\mathrm{Lu}_{2} \mathrm{MgAl}_{4} \mathrm{SiO}_{12}: \mathrm{Eu}^{2+}$ sample would also do great damage to the symmetry of the $\mathrm{Eu}^{2+}$ local coordinated environment, leading to the emergence of $\mathrm{Eu}^{3+}$ emission in $z=0.6-1$. Overall, Figure $7 \mathrm{~b}$ shows the increase of the Stokes shift and the FWHM of the emission spectra with the enhancement of the $z$ value owing to the contraction of the $\mathrm{EuO}_{8}$ polyhedron. Furthermore, the local structure evolution model through the replacement of the $\left[\mathrm{LuO}_{8}\right]$ polyhedra and $\left[\mathrm{AlO}_{4}\right]$ tetrahedron by the larger $\left[\mathrm{CaO}_{8}\right]$ and the similar $\left[\mathrm{GeO}_{4}\right]$ is presented in Figure $7 \mathrm{c}$, and a typical distortion can be observed due to the breaking of the symmetry of the $\left[\mathrm{EuO}_{8}\right]$ dodecahedron. Thus, the redshift and broadening 
emission band were mainly influenced by the enhancement of the polyhedral distortion.

\section{CONCLUSION}

A series of $\mathrm{Eu}^{2+}$-doped garnet-type phosphors were designed based on multiple substitution strategies to modify the chemical compositions. $\mathrm{Lu}_{2} \mathrm{MgAl}_{4} \mathrm{SiO}_{12}: \mathrm{Eu}^{2+}$ phosphor exhibited blue emission with an asymmetric emission band under $365 \mathrm{~nm}$ UV light excitation, which was ascribed to the two-site occupation of $\mathrm{Eu}^{2+}$ at $\mathrm{Lu}$ and Mg crystallographic sites, and accordingly, the emission peak positions moved about $15 \mathrm{~nm}$ to longer wavelengths with the increasing $\mathrm{Eu}^{2+}$ content. Moreover, the red-shift behavior from 463 to $503 \mathrm{~nm}$ along with the broadening emission band can be realized via replacing the $\mathrm{Mg}^{2+}$ with the $\mathrm{Ca}^{2+}$ in the $\mathrm{Lu}_{2} \mathrm{MgAl}_{4} \mathrm{SiO}_{12}: 1 \% \mathrm{Eu}^{2+}$ system. In the meantime, the chemical unit cosubstitution of $\left[\mathrm{Ca}^{2+}-\mathrm{Ge}^{4+}\right]$ for $\left[\mathrm{Lu}^{3+}-\mathrm{Al}^{3+}\right]$ has been successfully adopted to adjust the maximum peak of the PL from 463 to $523 \mathrm{~nm}$ and broadened the FWHM of the emission spectra. These changes in the PL spectra were caused by the enhancement of the polyhedral distortion in the $\mathrm{EuO}_{8}$ polyhedral with the increase in the amounts of $\mathrm{Ca}$ or $\mathrm{Ca}$ and Ge. This work demonstrated that it is efficient to design novel $\mathrm{Eu}^{2+}$-doped garnet-type phosphors based on the controlling of the chemical composition of the hosts via a cation substitution and the chemical unit substitution method to realize color-tunable emission.

\section{AUTHOR INFORMATION Corresponding Author \\ *xiazg@scut.edu.cn}

\section{ORCID}

Zhiguo Xia: oooo-0oo2-9670-3223

\section{Notes}

The authors declare no competing financial interest.

\section{ACKNOWLEDGMENT}

This research is supported by the National Natural Science Foundation of China (No. 51972118, 51722202 and 51572023), Natural Science Foundations of Beijing (2172036); Fundamental Research Funds for the Central Universities (FRF-TP-18-002C1).

\section{REFERENCES}

(1) Li, G.; Tian, Y.; Zhao, Y.; Lin, J. Recent progress in luminescence tuning of $\mathrm{Ce}^{3+}$ and $\mathrm{Eu}^{2+}$-activated phosphors for pc-WLEDs. Chem. Soc. Rev. 2015, 44 (23), 8688-713.

(2) Xia, Z.; Liu, Q. Progress in discovery and structural design of color conversion phosphors for LEDs. Prog. Mater. Sci. 2016, 84, 59-117.

(3) Qin, X.; Liu, X.; Huang, W.; Bettinelli, M.; Liu, X. Lanthanide-Activated Phosphors Based on 4f-5d Optical Transitions: Theoretical and Experimental Aspects. Chem. Rev. 2017, 117, 4488-4527.

(4) Im, W. B.; George, N.; Kurzman, J.; Brinkley, S.; Mikhailovsky, A.; Hu, J.; Chmelka, B. F.; DenBaars, S. P.; Seshadri, R. Efficient and color-tunable oxyfluoride solid solution phosphors for solid-state white lighting. Adv. Mater 2011, 23 (20), 2300-5.

(5) Dai, P. P.; Li, C.; Zhang, X. T.; Xu, J.; Chen, X.; Wang, X. L.; Jia, Y.; Wang, X.; Liu, Y. C. A single Eu ${ }^{2+}$-activated high-color-rendering oxychloride white-light phosphor for white-light-emitting diodes. Light: Sci. Appl. 2016, 5 (2), e16024.

(6) Xia, Z.; Meijerink, A. Ce ${ }^{3+}$-Doped garnet phosphors: composition modification, luminescence properties and applications. Chem. Soc. Rev. 2017, 46 (1), 275-299.

(7) Xie, R.-J.; Hirosaki, N.; Mitomo, M.; Suehiro, T.; Xu, X.; Tanaka, H. Photoluminescence of Rare-Earth-Doped Caalpha-SiAION Phosphors: Composition and Concentration Dependence. J. Am. Ceram. Soc. 2005, 88 (10), 2883-2888.

(8) Zhang, M.; Wang, J.; Ding, W.; Zhang, Q.; Su, Q. Luminescence properties of $\mathrm{M}_{2} \mathrm{MgSi}_{2} \mathrm{O}_{7}: \mathrm{Eu}^{2+}(\mathrm{M}=\mathrm{Ca}, \mathrm{Sr}$ ) phosphors and their effects on yellow and blue LEDs for solid-state lighting. Opt. Mater. 2007, 30 (4), 571-578.

(9) Denault, K. A.; George, N. C.; Paden, S. R.; Brinkley, S.; Mikhailovsky, A. A.; Neuefeind, J.; DenBaars, S. P.; Seshadri, R. A green-yellow emitting oxyfluoride solid solution phosphor $\mathrm{Sr}_{2} \mathrm{Ba}\left(\mathrm{AlO}_{4} \mathrm{~F}\right)_{1-x}\left(\mathrm{SiO}_{5}\right)_{x}: \mathrm{Ce}^{3+}$ for thermally stable, high color rendition solid state white lighting. J. Mater. Chem. 2012, 22 (35)

(10) Pust, P.; Weiler, V.; Hecht, C.; Tucks, A.; Wochnik, A. S.; Henss, A. K.; Wiechert, D.; Scheu, C.; Schmidt, P. J.; Schnick, W. Narrow-band red-emitting $\operatorname{Sr}\left[\mathrm{LiAl}_{3} \mathrm{~N}_{4}\right]: \mathrm{Eu}^{2+}$ as a next-generation LED-phosphor material. Nat. Mater. 2014, $13(9), 891-6$

(11) Wei, Y.; Gao, J.; Xing, G.; Li, G.; Dang, P.; Liang, S.; Huang, Y. S.; Lin, C. C.; Chan, T.-S.; Lin, J. Controllable $\mathrm{Eu}^{2+}$-Doped Orthophosphate Blue-/Red-Emitting Phosphors: Charge Compensation and Lattice-Strain Control. Inorg. Chem. 2019, 58 (9), 6376-6387.

(12) Shang, M.; Fan, J.; Lian, H.; Zhang, Y.; Geng, D.; Lin J. A double substitution of $\mathrm{Mg}^{2+}-\mathrm{Si}^{4+} / \mathrm{Ge}^{4+}$ for $\mathrm{Al}(1)^{3+}-\mathrm{Al}(2)^{3+}$ in $\mathrm{Ce}^{3+}$-doped garnet phosphor for white LEDs. Inorg. Chem. 2014, 53 (14), 7748-55.

(13) Chen, Y.; Feng, D.; Xu, S.; Zeng, S.; Wei, X. Synthesis and photoluminescence of $\mathrm{Eu}^{2+}$ doped $\mathrm{Lu}_{2} \mathrm{CaMg}_{2} \mathrm{Si}_{3} \mathrm{O}_{12}$ garnet phosphors. Mater. Lett. 2016, 164, 180-182.

(14) Zhang, X.; An, Z.; Dong, R.; Song, Y.; Zheng, K.; Sheng, Y.; Shi, Z.; Zou, H. Properties and Application of Single $\mathrm{Eu}^{2+}$-Activated Color Tuning Phosphors. ACS Sustain. Chem. \& Eng. 2019, 7 (12), 10724-10733.

(15) Berezovskaya, I. V.; Dotsenko, V. P.; Voloshinovskii, A. S.; Smola, S. S. Near infrared emission of $\mathrm{Eu}^{2+}$ ions in $\mathrm{Ca}_{3} \mathrm{Sc}_{2} \mathrm{Si}_{3} \mathrm{O}_{12}$. Chem. Phys. Lett. 2013, 585, 11-14.

(16) Wang, S. S.; Chen, W. T.; Li, Y.; Wang, J.; Sheu, H. S.; Liu, R. S. Neighboring-cation substitution tuning of photoluminescence by remote-controlled activator in phosphor lattice. J. Am. Chem. Soc. 2013, 135 (34), 125047.

(17) Li, G.; Lin, C. C.; Chen, W.-T.; Molokeev, M. S.; Atuchin, V. V.; Chiang, C.-Y.; Zhou, W.; Wang, C.-W.; Li, W.H.; Sheu, H.-S.; Chan, T.-S.; Ma, C.; Liu, R.-S. Photoluminescence Tuning via Cation Substitution in Oxonitridosilicate Phosphors: DFT Calculations, Different Site Occupations, and Luminescence Mechanisms. Chem. Mater. 2014, 26 (9), 2991-3001.

(18) Wang, L.; Xie, R. J.; Li, Y.; Wang, X.; Ma, C. G.; Luo, D.; Takeda, T.; Tsai, Y. T.; Liu, R. S.; Hirosaki, N. Ca $a_{1-x} \mathrm{Li}_{x} \mathrm{Al}_{1-}$ ${ }_{x} \mathrm{Si}_{1+x} \mathrm{~N}_{3}: \mathrm{Eu}^{2+}$ solid solutions as broadband, color-tunable and thermally robust red phosphors for superior color rendition 
white light-emitting diodes. Light: Sci. Appl. 2016, 5 (10), e16155.

(19) Huang, C.-H.; Wu, P.-J.; Lee, J.-F.; Chen, T.-M. $(\mathrm{Ca}, \mathrm{Mg}, \mathrm{Sr})_{9} \mathrm{Y}\left(\mathrm{PO}_{4}\right)_{7}: \mathrm{Eu}^{2+}, \mathrm{Mn}^{2+}$ : Phosphors for white-light near-UV LEDs through crystal field tuning and energy transfer. J. Mater. Chem. 2011, 21 (28).

(20) Liang, S.; Dang, P.; Li, G.; Wei, Y.; Wei, Y.; Lian, H.; Lin, J. New Insight for Luminescence Tuning Based on Interstitial sites Occupation of $\mathrm{Eu}^{2+}$ in $\mathrm{Sr}_{3} \mathrm{Al}_{2-x} \mathrm{SixO}_{5-x} \mathrm{~N}_{x} \mathrm{Cl}_{2}(x$ = 0-0.4). Adv. Opt. Mater. 2018, 6(22), 1800940.

(21) Qiao, J.; Zhang, Z.; Zhao, J.; Xia, Z. Tuning of the Compositions and Multiple Activator Sites toward SinglePhased White Emission in $\left(\mathrm{Ca}_{9-x} \mathrm{Sr}_{x}\right) \mathrm{MgK}\left(\mathrm{PO}_{4}\right)_{7}: \mathrm{Eu}^{2+}$ Phosphors for Solid-State Lighting. Inorg. Chem. 2019, 58 (8), 5006-5012.

(22) Xia, Z.; Ma, C.; Molokeev, M. S.; Liu, Q.; Rickert, K.; Poeppelmeier, K. R. Chemical Unit Cosubstitution and Tuning of Photoluminescence in the $\mathrm{Ca}_{2}\left(\mathrm{Al}_{1-x} \mathrm{Mg}_{x}\right)\left(\mathrm{Al}_{1-}\right.$ $\left.{ }_{x} \mathrm{Si}_{1+x}\right) \mathrm{O}_{7}: \mathrm{Eu}^{2+}$ Phosphor. J. Am. Chem. Soc. 2015, 137 (39), 12494-7.

(23) Prashantha, S. C.; Lakshminarasappa, B. N.; Nagabhushana, B. M. Photoluminescence and thermoluminescence studies of $\mathrm{Mg}_{2} \mathrm{SiO}_{4}: \mathrm{Eu}^{3+}$ nano phosphor. J. Alloys Compd. 2011, 509 (42), 10185-10189.

(24) Ding, X.; Zhu, G.; Geng, W.; Mikami, M.; Wang, Y. Novel blue and green phosphors obtained from $\mathrm{K}_{2} \mathrm{ZrSi}_{3} \mathrm{O}_{9}: \mathrm{Eu}^{2+}$ compounds with different charge compensation ions for LEDs under near-UV excitation. $J$. Mater. Chem. C 2015, 3, 6676-6685.

(25) Xiao, W.; Zhang, X.; Hao, Z.; Pan, G. H.; Luo, Y.; Zhang, L.; Zhang, J. Blue-emitting $\mathrm{K}_{2} \mathrm{Al}_{2} \mathrm{~B}_{2} \mathrm{O}_{7}: \mathrm{Eu}^{2+}$ phosphor with high thermal stability and high color purity for near-UVpumped white light-emitting diodes. Inorg. Chem. 2015, 54 (7), 3189-95.

(26) Leng, Z.; Li, R.; Li, L.; Xue, D.; Zhang, D.; Li, G.; Chen, X.; Zhang, Y. Preferential Neighboring SubstitutionTriggered Full Visible Spectrum Emission in Single-Phased $\mathrm{Ca}_{10.5-x} \mathrm{Mg}_{x}\left(\mathrm{PO}_{4}\right)_{7}$ :Eu ${ }^{2+}$ Phosphors for High Color-Rendering White LEDs. ACS Appl. Mater. Interfaces 2018, 10 (39), 33322-33334.

(27) Shang, M.; Liang, S.; Qu, N.; Lian, H.; Lin, J. Influence of Anion/Cation Substitution $\left(\mathrm{Sr}^{2+} \rightarrow \mathrm{Ba}^{2+}, \mathrm{Al}^{3+} \rightarrow \mathrm{Si}^{4+}, \mathrm{N}^{3-} \rightarrow\right.$ $\mathrm{O}^{2-}$ ) on Phase Transformation and Luminescence Properties of $\mathrm{Ba}_{3} \mathrm{Si}_{6} \mathrm{O}_{15}: \mathrm{Eu}^{2+}$ Phosphors. Chem. Mater. 2017, 29 (4), 1813-1829.

(28) Wang, Y.; Ding, J.; Wang, Y. $\mathrm{Ca}_{2-x} \mathrm{Y}_{1+x} \mathrm{Zr}_{2-}$ ${ }_{x} \mathrm{Al}_{3+x} \mathrm{O}_{12}: \mathrm{Ce}^{3+}$ : Solid Solution Design toward the Green Emission Garnet Structure Phosphor for Near-UV LEDs and Their Luminescence Properties. The J. Phys. Chem. C 2017, 121 (48), 27018-27028.

(29) Denault, K. A.; Brgoch, J.; Gaultois, M. W.; Mikhailovsky, A.; Petry, R.; Winkler, H.; DenBaars, S. P.; Seshadri, R. Consequences of Optimal Bond Valence on Structural Rigidity and Improved Luminescence Properties in $\mathrm{Sr}_{x} \mathrm{Ba}_{2-x} \mathrm{SiO}_{4}: \mathrm{Eu}^{2+}$ Orthosilicate Phosphors. Chem. Mater. 2014, 26 (7), 2275-2282.

(30) Baur, W. H. The geometry of polyhedral distortions. Predictive relationships for the phosphate group. Acta Crystallographica Section B Structural Crystallography and Crystal Chemistry 1974, 30 (5), 1195-1215. 


\title{
Multiple substitution strategies toward tunable luminescence in $\mathrm{Lu}_{2} \mathrm{MgAl}_{4} \mathrm{SiO}_{12}: \mathrm{Eu}^{2+}$ phosphors
}

\author{
Zhiqiang Ming†, Jianwei Qiao†, Maxim S. Molokeev $₫, \S, \perp$, Jing Zhao† Hendrik C. Swart ${ }^{\star}$ and Zhiguo \\ $X i a^{*},+, \diamond$
}

\section{For Table of Contents Only}

The equivalent or hetervalent substitution strategy is an efficient way to stimulate photoluminescence tuning or to optimize the luminescence performances of phosphor materials. Herein, two substitution approaches to control the luminescence behavior of $\mathrm{Lu}_{2} \mathrm{MgAl}_{4} \mathrm{SiO}_{12}: \mathrm{Eu}^{2+}$ phosphor is implemented. The proposed approaches on equivalent or hetervalent substitution can contribute to the developing of $\mathrm{Eu}^{2+}$-activated garnet-type phosphors with regulating luminescence performance and further initiate research discovering new phosphors for white light-emitting diodes.

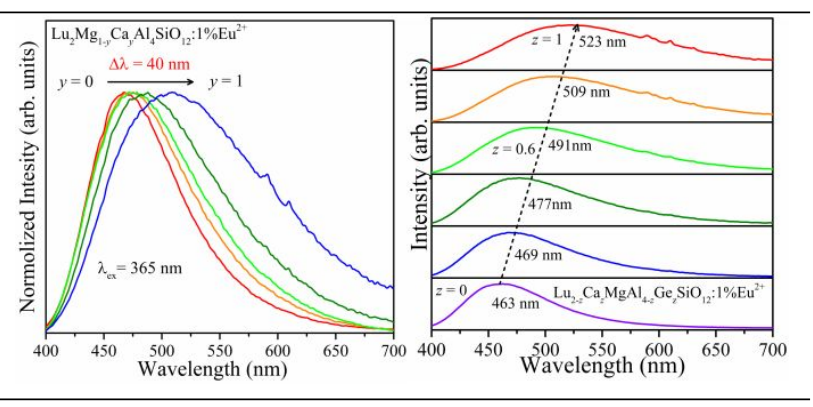

